\section{Four Novel Swedish Rose Cultivars}

\author{
B. Ulrika Carlson-Nilsson \\ Balsgård, Department of Crop Science, Swedish University of Agricultural \\ Sciences, Fjälkestadsvägen 459, SE-291 94 Kristianstad, Sweden
}

Additional index words. Rosa, breeding, winter-hardiness, L83, ornamentals

The first four rose cultivars produced at Balsgård, Swedish Univ. of Agricultural Sciences, were released in 2000. They are expected to survive in USDA plant hardiness zones 4-7, depending on cultivar, and are suitable for use as landscape roses or home garden plants. Their growth habit is best described as intermediate between bush roses and climbers.

The rose (Rosa L., Rosaceae Juss.) is the most popular garden plant in Sweden, as well as in many other countries. According to the USDA plant hardiness zone map, Sweden includes approximately hardiness zones $3-7$. The hybrid tea rose [Rosa L. (Hybrid Tea Group)] is the most popular type of rose. It does not survive consistently in climates colder than hardiness zone 5 (Collicutt, 1992). Many of the rose cultivars used by Swedish gardeners are imported from countries south of Sweden and are not acclimatized to the Swedish boreal vegetation zone (Walter, 1979). They flower recurrently, but often survive only a year or so. In the northern parts of Sweden, the number of sufficiently hardy cultivars is very limited. Only a few cultivars that perform more like indigenous species of wild Rosa L. are completely hardy in this climate.

\section{Rose Breeding Program at Balsgård, Sweden}

A breeding program for hardy roses was initiated by Viktor Trajkovski at Balsgård $\left(56^{\circ} \mathrm{N}, 14^{\circ} \mathrm{E}\right)$, Dept. of Horticultural Plant Breeding, Swedish Univ. of Agricultural Sciences, in 1985. Ann-Sofie Brackman became responsible for the breeding program in 1988 and was followed by Ulrika Carlson-Nilsson in 1991. The primary objective was to combine winter-hardiness, recurrent flowering, and ornamental value with resistance to important rose diseases like blackspot [Marssonina rosae (Lib.) Died.], powdery mildew [Sphaerotheca pannosa (Wallr. ex Fr.) Lév.], and diseases caused by the genus Phragmidium Link. Also, as a secondary objective, the cultivars selected should be suitable for growing on their own roots as they would be able to survive and regenerate from below ground in the event that the plants are winter-killed to ground level.

Contacts were established abroad with

Received for publication 29 May 2002. Accepted for publication 7 Jan. 2003. I am very grateful to F. Svejda for kindly providing L83 for use in the crosses. The work was funded by grants from the Swedish Research Council for Forestry and Agriculture, Swedish Association for Leisure Gardeners, Swedish Federation of Allotment and Leisure Gardeners, and Swedish Board of Agriculture. peers engaged in breeding program research with similar aims. Some of these programs were described by Collicutt (1992), Marshall and Collicutt (1992), and Ogilvie and Arnold (1992). Different selections originating from Canadian breeding programs, mainly at the former Agriculture Canada Plant Research Centre in Ottawa, were kindly provided for use in the Swedish breeding work.

Garden-rose cultivars with recurrent flowering and attractive horticultural appearance were hybridized with hardy disease-resistant species, cultivars, and selections. The most promising hybrids were achieved using cultivars like 'Allotria', 'Friesia' ('Sunsprite'), 'Nina Weibull', or 'Queen Elizabeth' as pistillate parents and selected seedlings from scotch rose (Rosa pimpinellifolia L.) or the Canadian selection L83 (originating from the Plant Research Centre in Ottawa) as pollen donors. L83 was obtained by Svejda (1988) as a hybrid between Rosa $\times$ kordesii Wulff and a rose selection G49. L83 combines high levels of winter-hardiness, recurrent flowering, and resistance to blackspot and powdery mildew.

Breeding for resistance to blackspot has been of increasing importance in the Swedish breeding program since 1992 . This disease is a very serious problem in Swedish gardens. Seedlings as well as different cultivars and rose species have been evaluated for possible resistance to blackspot when exposed to natural field infection (Carlson-Nilsson, 2000, 2002) as well as to artificial inoculation in the greenhouse (Carlson-Nilsson, 2002).

\section{Origin}

The first rose cultivars from Balsgård were released in 2000. They are named 'Anna' (BRo0611A), 'Irma' (BRo1227K), 'Balsgårds Balder' (BRo8733P), and 'Balsgårds Freja' (BRo8752P) (Fig. 1). The names of the cultivars Anna and Irma are approved as registered trademarks with the Swedish Patent and Registration Office. The names 'Anna' and 'Irma' were chosen after the names of the breeder's grandmothers. 'Balsgårds Balder' and 'Balsgårds Freja' are named after two gods in Nordic mythology.

The use of tetraploid amphidiploids developed from resistant diploid species has been suggested as a method for obtaining resistance (Byrne et al., 1996). Rosa ×kordessii Wulff, one parent of the Canadian germplasm L83, is an amphidiploid. The other parent, G49, was obtained from open pollination (herein designated op) of a tetraploid seedling, G12, in turn obtained from op of the usually sterile hybrid 'Max Graf'.

L83 is the pollen donor to all four cultivars. Both 'Anna' and 'Irma' have 'Friesia' ('Sunsprite') (Kordes) as female parent (Fig. 2), whereas 'Balsgårds Balder' and 'Balsgårds Freja' have 'Nina Weibull' (Poulsen) and 'Sympathie' (Kordes), respectively, as pistillate parent (Figs. 3 and 4).
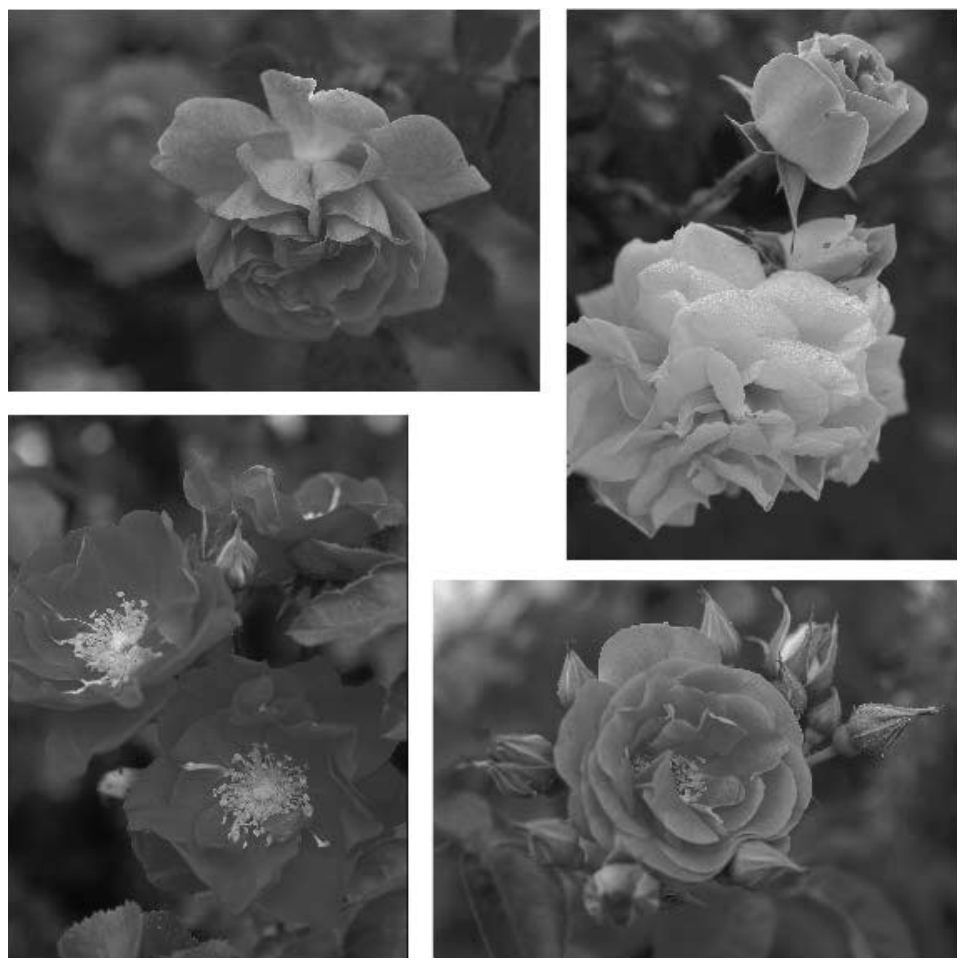

Fig. 1. (upper left) 'Anna' BRo0611A, (upper right) 'Irma' BRo1227K, (lower left) 'Balsgårds Balder' BRo8733P, and (lower right) 'Balsgårds Freja' BRo8752P. Photographs: (C2001 Björn Hansson, Ola Cappelins väg 9, SE-277 30 Kivik, Sweden. All rights reserved. 


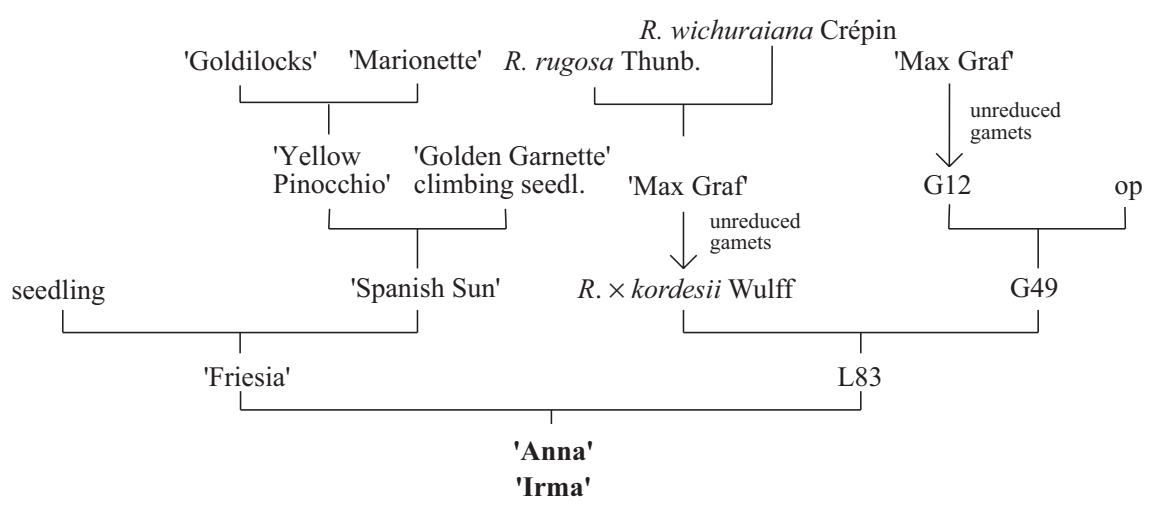

Fig. 2. Parentage of 'Anna' and 'Irma'.

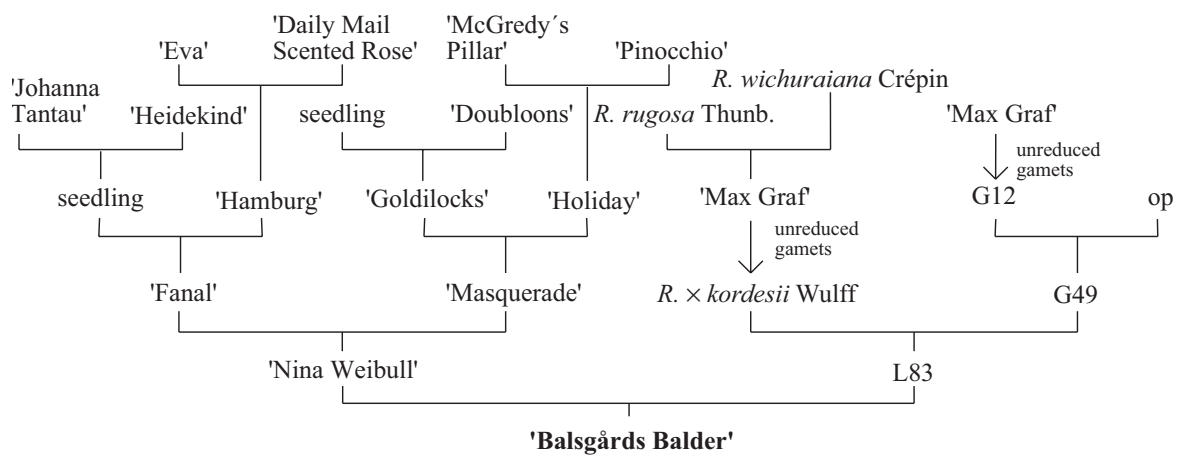

Fig. 3. Parentage of 'Balsgårds Balder'.

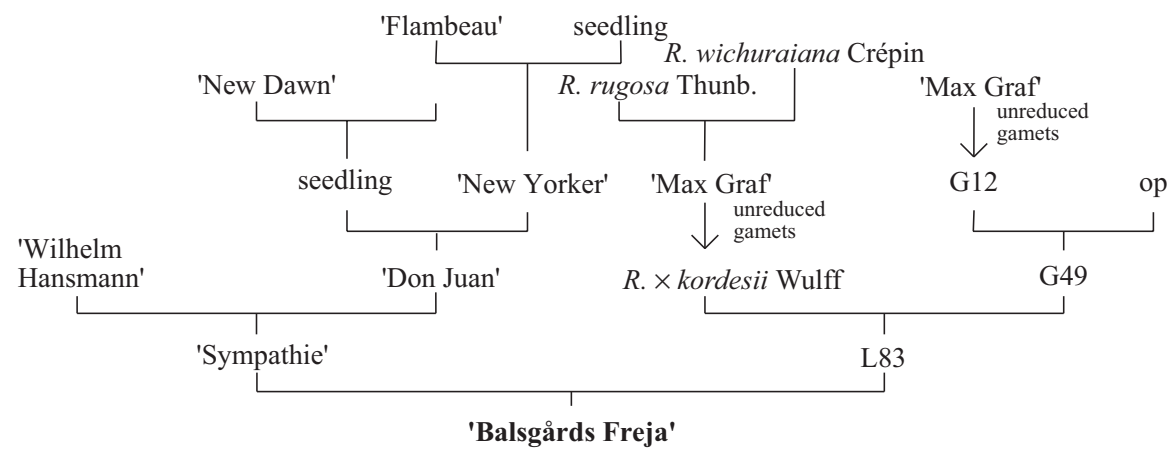

Fig. 4. Parentage of 'Balsgårds Freja'.

'Balsgårds Balder' and 'Balsgårds Freja' were selected especially for the severe climate of northern Sweden (USDA plant hardiness zones 4-5), whereas 'Anna' and 'Irma' have been grown mainly in the southern part of Sweden, where the climate is considerably milder (USDA zone 7). Also, the latter two cultivars are being evaluated currently in the northern part of the country.

\section{Description}

'Balsgårds Balder'. 'Balsgårds Balder' is a relatively open and spreading shrub rose, reaching a height and spread of 1.5-2.0 $\mathrm{m}$ at Balsgård. The prickles are deep concave, $\approx 10$ per $10-\mathrm{cm}$ stem section. The foliage is glabrous and green [139A, Royal Horticultural Society (RHS), 1986] above and yellow-green (RHS 147B) beneath. There are seven ovate, accu- minate, serrate leaflets; the terminal leaflet is 5.1 to $6.6 \mathrm{~cm}$ long (avg. $5.8 \mathrm{~cm}$ ) $\times 3.2$ to 4.8 $\mathrm{cm}$ wide (avg. $3.7 \mathrm{~cm}$ ). Slightly fragrant flowers are produced on current season and older stems. The flowers are semi-double $(\approx 15$ petals $)$ and mainly produced in sprays. Newly opened flowers are bright red-purple (RHS 57A) on the upper side, and dark pink (RHS 67B) on the lower side (Fig. 1). The upper side fades to a more pink color. Bright yellow stamens become fully apparent when the flower is open. The sepals have medium extensions. Hips (globose) are occasionally produced.

'Balsgårds Balder' is very hardy, vigorous, and has so far demonstrated the best hardiness of the four new cultivars. It has been tested in Sweden in USDA plant hardiness zone 4, where it survives without problems. Stem dieback to the snow line does occur, but regrowth occurs from the lower stems. Whether this cultivar is able to grow and survive in even colder regions remains to be tested.

Flowering is divided into two main periods. The first period lasts 3 to 6 weeks, beginning at the end of June, and the second period is also 3 to 6 weeks in duration and starts in early to mid-August. Occasionally, a shorter third flowering period can be observed in mid-October. It produces some hips, and removal of old flowers should, therefore, promote recurrent flowering.

'Balsgårds Balder' has good field resistance to local populations of blackspot and powdery mildew, but is sensitive to rust and leaf spot [Sphaceloma rosarum (Pass.) Jenkins]

'Balsgårds Freja'. 'Balsgårds Freja' is a relatively open and spreading shrub rose, reaching a height and spread of 1.5-2.0 m at Balsgård. The prickles are deep concave, $\approx 15$ per $10-\mathrm{cm}$ stem section. The foliage is glabrous and green (RHS 137A) above and yellow-green (RHS 146B) beneath. There are seven ovate, accuminate, serrate leaflets; the terminal leaflet is 4.9 to $6.6 \mathrm{~cm}$ long (avg. $5.4 \mathrm{~cm}$ ) $\times 3.0$ to 5.4 $\mathrm{cm}$ wide (avg. $3.7 \mathrm{~cm})$. Slightly fragrant flowers are produced on current season and older stems. The flowers are double ( $>20$ petals) and mainly produced in sprays. Newly opened flowers are bright pink on the upper side (RHS 67C) with a duller pink (RHS 64D) on the lower side (Fig. 1). The flower fades to a lighter shade of pink, (RHS 73BC). Bright yellow stamens become apparent when the flower is fully open. The sepals are without extensions. Hips (globose) are frequently produced.

'Balsgårds Freja' is vigorous and hardy. However, this cultivar has shown less hardiness in USDA plant hardiness zone 4 compared to 'Balsgårds Balder', but grows very well in zone 5.

The flowers are produced from the end of June until September in the south of Sweden, USDA plant hardiness zone 7. Since the cultivar is fertile, old flowers should be removed to promote recurrent flowering.

This cultivar has very good field resistance to local populations of powdery mildew and rust, but some plants have shown slight infections of leaf spot and blackspot.

'Anna'. 'Anna' is an upright, narrow shrub rose, reaching a height and spread of $\approx 2.0 \times 1.5$ $\mathrm{m}$ at Balsgård. The prickles are deep concave, $\approx 10$ per 10 -cm stem section. The foliage is glabrous and green (RHS 139A) above and yellow-green (RHS 147B) beneath. There are five to seven ovate, accuminate, serrate leaflets; the terminal leaflet is 4.6 to $6.3 \mathrm{~cm}$ long (avg. $5.3 \mathrm{~cm}) \times 2.9$ to $3.9 \mathrm{~cm}$ wide (avg. $3.4 \mathrm{~cm}$ ). Pleasantly fragrant flowers are produced on current season and older stems. The flowers are $8-9 \mathrm{~cm}$ in diameter and double ( $>20$ petals). They are pink (RHS 54C) with yellow tones in the middle of the flower. Inner petals often show a yellow stripe and are somewhat undulated (Fig. 1). Bright yellow stamens become apparent when the flower is open. The sepals have weak extensions. Hips (globose) are occasionally produced.

'Anna' is a vigorous cultivar and has so far been evaluated only at Balsgård, USDA plant hardiness zone 7 , where the hardiness 
has been very good. Since summer 2001, it has been grown for evaluation in zone 4 , and the preliminary results are promising.

This cultivar flowers from July to October with some breaks. The main flowering period is the first half of July. It produces some hips, and removal of old flowers should, therefore, promote recurrent flowering.

'Anna' has shown excellent field resistance to local populations of powdery mildew and rust at Balsgård. Infections of blackspot and leaf spot, however, have been observed.

'Irma'. 'Irma' is a relatively open and spreading rose, reaching a height and spread of $\approx 1.6 \times 1.0 \mathrm{~m}$. The prickles are deep concave, $\approx 20$ per $10-\mathrm{cm}$ section. Foliage is glabrous, coriaceous and green (RHS 137A) above and yellow-green (RHS 146B) beneath. There are seven ovate accuminate, serrate leaflets; the terminal leaflet is 4.7 to $6.2 \mathrm{~cm}$ long (avg. $5.4 \mathrm{~cm}$ ) $\times 2.6$ to $4.2 \mathrm{~cm}$ wide (avg. $3.3 \mathrm{~cm}$ ). Pleasantly fragrant flowers are produced on current season and older stems. The flowers are $8-10 \mathrm{~cm}$ in diameter and double ( $>20$ petals). They are light pink (RHS 65CD) with a yellowish midsection and are produced singly or in sprays (Fig. 1). Although the flowers have many petals, they often open up enough to show the yellow-pink stamens. The sepals have weak extensions. Hips (globose) are occasionally produced.

'Irma' is shorter compared to the other three cultivars. Just like 'Anna' it has so far been evaluated only at Balsgård, USDA plant hardiness zone 7, where it has shown good hardiness. Since summer 2001, it has also been evaluated in zone 4 , and the preliminary results are promising.

The cultivar flowers from July until October with minor breaks. The main flowering period is in July. It produces some hips, and removal of old flowers, therefore, should promote recurrent flowering.

'Irma' has shown excellent field resistance to local populations of powdery mildew and rust at Balsgård, but minor infections of blackspot as well as leaf spot have been observed in some years.

\section{Propagation and Uses}

All four Balsgård cultivars should be grown on their own roots and can be propagated by softwood stem cuttings or tissue culture.

The cultivars are suitable for several purposes both for landscape applications and home gardens. They can be planted individually (as a shrub rose or climber) or in mass plantations (e.g., as a hedge).

\section{Availability}

'Anna' and 'Irma' are registered as approved trademarks with the Swedish Patent and Registration Office (no. 355631 and no. 354623 , respectively). Cultivar tests outside of Sweden have not been performed. The Foundation of the Swedish Horticultural Elite Plant
Station (Fjälkestadsvägen 459, SE-29194 Kristianstad, Sweden) is propagating the cultivars. Persons interested in scientific testing of the cultivars should contact them. Balsgård, Dept. of Crop Science, Swedish Univ. of Agricultural Sciences, reserves the right to collect royalties from these four cultivars.

\section{Literature Cited}

Byrne, D.H., W. Black, Y. Ma, and H.B. Pemberton. 1996. The use of amphidiploidy in the development of blackspot resistant rose germplasm. Acta Hort. 424:269-272.

Carlson-Nilsson, B.U. 2000. Resistance to Marssonina rosae in Rosa L. seedlings obtained from controlled crosses including germplasm L83. Acta Agr. Scand., Sect. B, Soil and Plant Sci. 50:176-182.

Carlson-Nilsson, B.U. 2002. Variation in Rosa with emphasis on the improvement of winter hardiness and resistance to Marssonina rosae (blackspot). PhD Diss., Dept. of Crop Sci., Swedish Univ.of Agr. Sci., Sweden.

Collicutt,L. 1992. Hardy-rose breeding at the Morden research station. HortScience 27:1070, 1147.

Marshall, H.H. and L.M. Collicutt. 1992. Breeding hardy roses. Can. Rose Ann. 27-35.

Ogilvie, I.S. and N.P. Arnold. 1992. Roses from the North. Horticulture 2:26-32.

Royal Horticultural Society Colour Chart. 1986. Royal Hort. Soc., London.

Svejda, F. 1988. Rose germplasm L83. HortScience 23:415-416.

Walter, H. 1979. Vegetation of the earth and ecological systems of the geo-biosphere. 2nd ed. Springer-Verlag, New York. 